\title{
EL MODELO DE FEJERSKOV Y MANJI COMO MARCO DESCRIPTIVO DENTRO DE LAS INVESTIGACIONES SOBRE CARIES DENTAL DEL GRUPO DE INVESTIGACIÓN GASTROHNUP DE LA UNIVERSIDAD DEL VALLE DE CALI, COLOMBIA
}

\author{
María CRISTina ARANGo de la CRUZ, O.D. ${ }^{1}$, \\ Carlos Alberto Velasco-BeníteZ, M.D. ${ }^{2}$
}

\section{RESUMEN}

El actual modelo de la aparición de caries dental depende de factores como el huésped, las bacterias, la dieta y el tiempo, que alteran el equilibrio entre la sustancia dental produciendo su desmineralización. El modelo de Fejerskov y Manji, de 1990, fue adaptado como marco descriptivo en la investigación sobre caries dental en niños con infección por VIH/SIDA. Este es un modelo biológico teniendo en cuenta que el paciente con infección por VIH/SIDA, presenta alteración en la respuesta inmune a las bacterias, siendo esta una de las causas de caries dental.

Palabras claves: Modelo de Fejerskov y Manji, Caries dental, Infección por VIH/SIDA, Niños

\section{INTRODUCCIÓN}

Actualmente existe un modelo clásico de la aparición de la caries dental, el cual promueve que el desarrollo de la caries dental en un individuo, depende de varios factores entre los cuales está el huésped, las bacterias, la dieta y el tiempo en que todos estos factores estén interactuando ${ }^{1-3}$, logrando alterar el equilibrio en la sustancia dental y produciendo su desmineralización. A su vez estos cambios biológicos están enmarcados en un componente social y estilo de vida, los cuales actúan como cofactores para el desarrollo de la caries dental ${ }^{3}$.

\section{CARIES DENTAL EN NIÑOS CON INFECCIÓN POR VIH/SIDA}

Entre las patologías que aquejan a los niños con infección por el VIH/SIDA, se encuentra la caries dental, entidad prevenible si se detecta en sus etapas iniciales y evita mayores complicaciones. El objetivo principal del trabajo de investigación Prevalencia de

${ }^{1}$ Odontopediatra. Profesora. Escuela de Odontología. Universidad del Valle. Cali, Colombia

${ }^{2}$ Pediatra. Gastroenterólogo. Profesor titular. Departamento de Pediatría. Universidad del Valle. Cali, Colombia

Recibido para publicación: enero 15, 2015

Aceptado para publicación: agosto 14, 2015

\section{SUMMARY}

The current model for the development of dental caries depends on factors such as host bacteria, diet and time, altering the balance between substance producing dental demineralisation. Fejerskov model and Manji, 1990, was adapted as a descriptive framework in research on dental caries in children with HIV/AIDS. This is a biological model taking into account the patient with HIV/AIDS, has impaired immune response to bacteria, being one of the causes of dental caries.

\section{Key words: Model Fejerskov and Manji, Dental caries, HIV/AIDS, Children}

caries dental en niños VIH/SIDA con trasmisión vertical de la Clínica Pediátrica de VIH de Cali, Colombia, y sus posibles factores asociados año 2013, del Grupo de Investigación en Gastroenterología, Hepatología y Nutrición Pediátrica Gastrohnup de la Universidad del Valle, fue determinar la prevalencia de caries dental en niños con infección por el VIH/SIDA de transmisión vertical de la Clínica Pediátrica de VIH de Cali, Colombia, 2013, y establecer posibles asociaciones con factores de riesgo para la caries dental. Fue un estudio descriptivo, tipo prevalencia, en 101 historias clínicas de niños entre 1 y 17 años con diagnóstico de infección por el VIH/SIDA con transmisión vertical de clínica VIH Pediátrico de Cali, Colombia. Se incluyó análisis multivariado con variables sociodemográficas, paraclínicas, nutricionales, odontológicas. El diagnóstico de caries fue el criterio ICDAS, realizado en la Clínica Pediátrica de VIH de Cali, Colombia. Se ajustó por variables confusoras para determinar posibles factores de riesgo. El proyecto fue avalado por los Comité de Ética Institucionales. Entre los resultados de la investigación, se tiene que la prevalencia de caries en niños con infección por el VIH con el índice ICDAS fue del 81,12\% (IC95\% 73,43-88,94) con un índice dientes cariados, obturados y perdidos de 5,68 DE 5,48. En dentición permanente la prevalencia fue del $74,16 \%$ (IC95\% 64,88-83,43), y en dentición temporal del 
73,01\% (IC95\% 61,74-84,28). Estas prevalencias disminuyen al aplicar el índice OMS siendo COP/ceo $34,65 \%$ (IC95\% 25,21-44,09) con un índice de 1,5 (DE 1,89). No se encontró asociación estadísticamente significativa con ninguna variable socioeconómica, ni inmunológica. Los pacientes con inmunodepresión moderada y severa presentaban un OR 1.13 (IC95\% 0.33-3.81) $\mathrm{p}=0.84$, siendo no estadísticamente significante. Las únicas asociaciones que mostraron significancia fueron el índice de placa con un OR de 4,58 (IC95\% 1.44-14.55) $\mathrm{p}=0,006$ y la historia pasada de caries. En conclusión, los pacientes con infección por el VIH de la Clínica Pediátrica de VIH de Cali, Colombia, presentan alta prevalencia de caries cuando se valoran lesiones precavitacionales y cavitacionales, encontrándose necesidad de manejar tratamientos preventivos de lesiones tempranas, y mayor control de su higiene oral. No se encuentra asociación entre el estadio inmunológico ni clínico y el proceso de caries, esto posiblemente siendo justificado por el excelente control de los pacientes en la institución, lográndose inmunológicamente estar estables, no siendo este punto un factor de riesgo adicional. La prevalencia si se manejan índices cavitacionales es baja.

\section{El modelo de Fejerskov y Manji}

Para este estudio, se usó una adaptación del planteado por Fejerskov \& Manji, 1990, desarrollando un modelo biológico para la explicación del proceso de caries dental en pacientes con infección por el VIH. Este modelo plantea que teniendo en cuenta que el paciente con la infección por el VIH, presenta por su condición, una alteración en la respuesta inmune a los agentes agresores, entre ellos las bacterias, y siendo estas una de las causantes del proceso de caries dental, habría unos factores biológicos adicionales a los claramente establecidos en un paciente normal, que predisponen la aparición de caries dental en los pacientes con la infección por el VIH pediátrico ${ }^{4}$.

Primero, la infiltración del virus de la infección por el VIH y la proliferación de los Linfocitos CD8 en las glándulas salivales ${ }^{5}$ junto con el uso de terapia HAART ${ }^{6}$, disminuyen el flujo salival (parcial o total), lo cual lleva a alteraciones en la composición de la saliva logrando cambiar la flora normal de la cavidad oral, impidiendo inmunológicamente que la saliva cumpla sus funciones protectoras de taponamiento, aclaramiento, equilibrio de minerales y barrido de la placa bacteriana, teniendo como consecuencia la aparición de caries dental en los pacientes con la infección por el VIH, por permitir el establecimiento de una placa madura que lleva a la permanencia de múltiples bacterias como lo reporta Takahashi et al. ${ }^{7}$, que propone una ecología múltiple y mixta de bacterias en el proceso de caries. Estos microorganismos especialmente el Streptococcus mutans $^{3}$, tienen la habilidad de la adhesión a la estructura dental, encontrándose aumentada esta adhesión en los defectos del esmalte, comunes en los pacientes con la infección por el VIH.

Segundo, adicionalmente al componente inmunológico, el uso de la terapia HAART en el paciente pediátrico, que contiene una alta concentración de glucosa, actúa como sustrato para el metabolismo bacteriano, bajando el $\mathrm{pH}$ y produciendo la desmineralización dental, no siendo el uso de la terapia HAART exclusivamente la causa de la caries ${ }^{1}$, ya que el Streptococcus mutans y su capacidad para metabolizar ácidos y producir su acción cariogénica, es regulado principalmente por factores ambientales como la dieta, su frecuencia al día, tanto en comida como bebidas, en el número de ingestas diaria de carbohidratos, principalmente la sacarosa, el momento del ser adquirido ${ }^{8}$. Teniendo en cuenta que el tratamiento antirretroviral al niño, se complica, por la cantidad de veces en el día de la toma, la falta de presentaciones pediátricas, el sabor desagradable, y el volumen elevado de los preparados, esto podría ser un factor predisponente para la caries dental.

Tercero, la mala higiene oral, una dieta rica en carbohidratos aumentan el riesgo de caries dental en los pacientes con infección por el $\mathrm{VIH}^{3,9-13}$ ya que su composición, número de veces en el día de su consumo, la estructura del diente y la cantidad de bacterias, son reguladores del proceso de caries.

Cuarto, se sugiere que la prevalencia de caries en los pacientes con la infección por el VIH pediátrico, es debido a los factores relacionados con la enfermedad, estos incluyen el nivel socioeconómico, el compromiso inmunológico, el uso de medicamentos (tiempo), antibióticos, antifúngicos y también antirretrovirales como el AZT (zidovudina), la dieta alta en carbohidratos, necesaria para el reemplazo proteico (terapia hipernutricional), la inflamación gingival y el uso de medicamentos azucarados ${ }^{14}$. 
Por otro lado, la dieta vista desde el punto de vista sistémico, actúa como factor de riesgo para el desarrollo de defectos en el esmalte en dentición permanente, cuando el paciente ha presentado desnutrición o bajo peso $^{15}$.

Adicionalmente, y bajo una perspectiva de determinación social de la salud enfermedad, la relación entre la condición social y vulnerabilidad de estos pacientes, hace que se deban desarrollar planes de atención enfocadas a disminuir su riesgo ${ }^{16}$. La presencia de lesiones y manifestaciones en cavidad oral, bien sea caries dental o lesiones orales específicas, pueden generar cambios en la apariencia facial, dificultad para hablar, disfagia, xerostomía, mala higiene oral, dolor y molestias que puede alterar seriamente el estado de salud y calidad de vida de los pacientes ${ }^{17}$ ya que se asocia a desnutrición, y está ligado estrechamente a condiciones sociales de alta marginación y limitado acceso a programas e instituciones de salud ${ }^{18}$.

\section{REFERENCIAS}

1. Rezaei-Soufi L, Davoodi P, Abdolsamadi HR, Jazaeri M, Malekzadeh H. Dental caries prevalence in human immunodeficiency virus infected patients receiving highly active anti-retroviral therapy in kermanshah, Iran. Cell J 2014; 16: 73-78

2. Cavasinjc MG. Dental and periodontal diseases in HIV+ patients. BJID 2009: 13-17

3. Fejerskov O, Kidd E. Dental Caries: The Disease and its Clinical Management. Second Edition. Copenhagen, Denmark: Blackwell Munksgaard Ltda; 2008

4. Fine D, Tofsky N, Nelson E, Schoen D, Barasch A. Clinical implications of the oral manifestations of HIV infection in children. Dent Clin NAm 2003; 47: 159-174

5. Cavasin Filho JC, Giovani EM. Xerostomy, dental caries and periodontal disease in HIV+ patients. Braz $\mathrm{J}$ Infect Dis 2009; 13: 13-17

6. Nittayananta, Talungch, Jaruratanasirikul, Silpapojakul, Chayakul, Nilmanat et al. Effects of long-term use of HAART on oral health status of HIV infected subjects. J Oral Pathol Med 2010; 39: 397-406

7. Takahashi N, Nyvad B. The Role of Bacteria in the Caries Process: Ecological Perspectives. J Dent Res 2011; 90: 294

8. Berkowitz RJ. Mutans streptococci: Acquisition and transmission. Pediatr Dent 2006; 28: 106-109

9. Navazesh M, Mulligan R, Barrón Y, Redford M, Greenspan $D$, Alves M. A 4-year longitudinal evaluation of xerostomia and salivary gland hypofunction in the Women's Interagency HIV Study participants. Oral Surg Oral Med Oral Pathol Oral Radiol Endod 2003; 95: 693-698

10. American Academy of Pediatric Dentistry. Guideline on infant oral health care. Pediatr Dent 2006; 28 (Suppl): 6972

11. Tinanoff N, O'Sullivan DM. Early childhood caries: Overview and recent findings. Pediatr Dent 1997; 19: 1216

12. Cavasinjc MG. Dental and periodontal diseases in HIV+ patients. BJID 2009: 13-17

13. American Academy of Pediatric Dentistry. Policy on early childhood caries (ECC): Classifications, consequences, and preventive strategies. Pediatr. Dent 2008; 29 (Suppl): 39-41

14. Vieira AR, de Souza IP, Modesto A, Castro GF, Vianna R. Gingival status of HIV+ children and the correlation with caries incidence and immunologic profile. Pediatr Dent 1998; 20: 169-172

15. Nelson JM, Lombardi AG, Asaad WG, Kirchner HL. Dental Caries and Enamel Defects in Very Low Birth Weight Adolescents S. Caries Res 2010; 44: 509-518

16. Estrada JH. Manifestaciones orales de la infección por $\mathrm{VIH} /$ sida en niños y adolescentes: aspectos clínicos, epidemiología y pautas de tratamiento. Univ Odontol 2011; 30: 37-50

17. Buczynski A, Castro G, Ribeiro de Souza P. Impacto da saúde bucal na qualidade de vida de crianças infectadas pelo HIV: revisão de literatura. Ciencia y Salud 2008; 13:1797-1805

18. Gaitán-Cepeda LA, Sánchez-Vargas LO, Pavia-Ruz N, Muñoz-Hernández R, Villegas-Ham J, CaballosSalobreña A. Candida bucal en niños mexicanos con VIH/sida, desnutrición o marginación social. Rev Panam Salud Pública 2012; 31: 48-53 


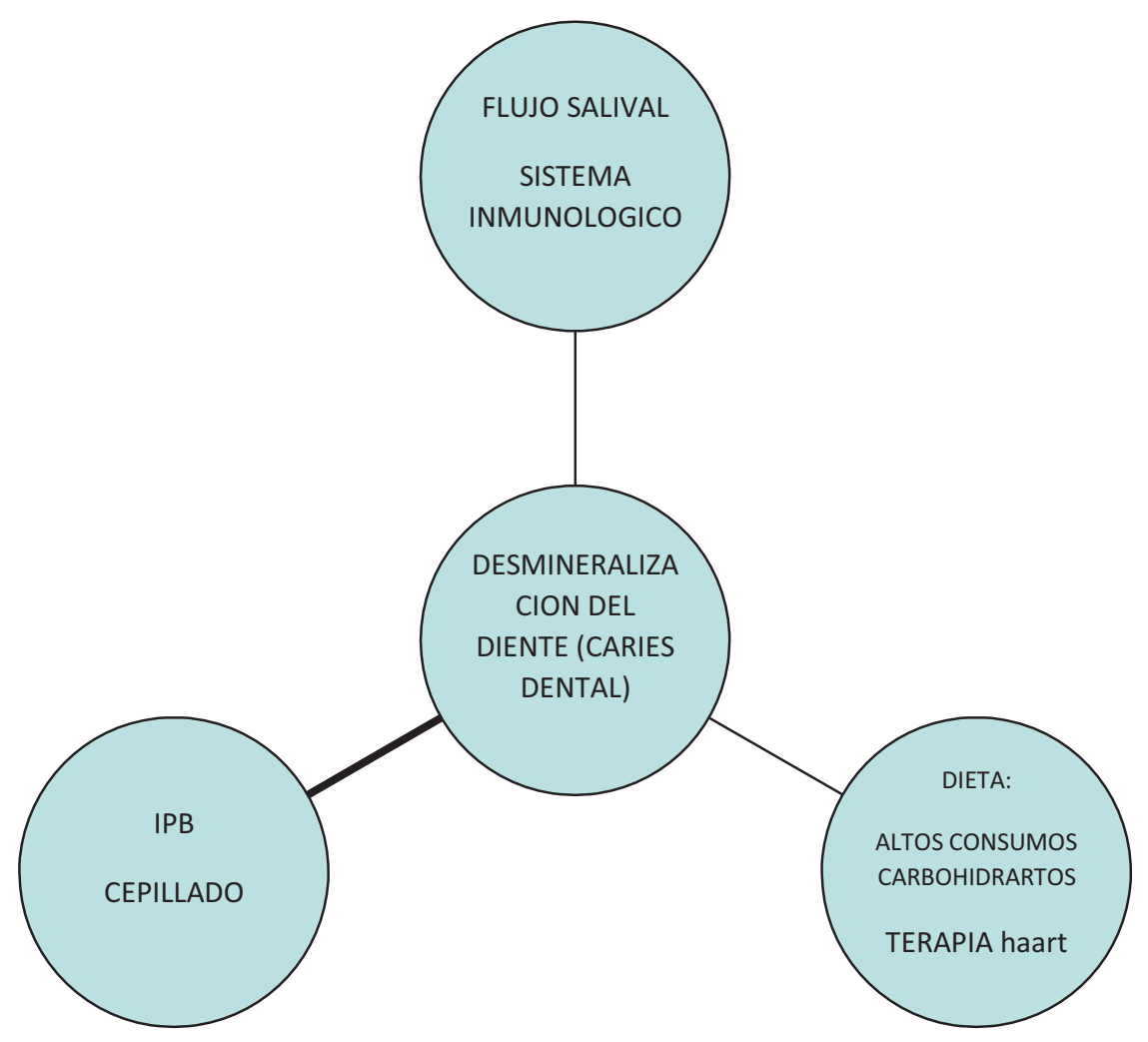

Figura 1. Marco teórico Factores de riesgo para la caries dental. 